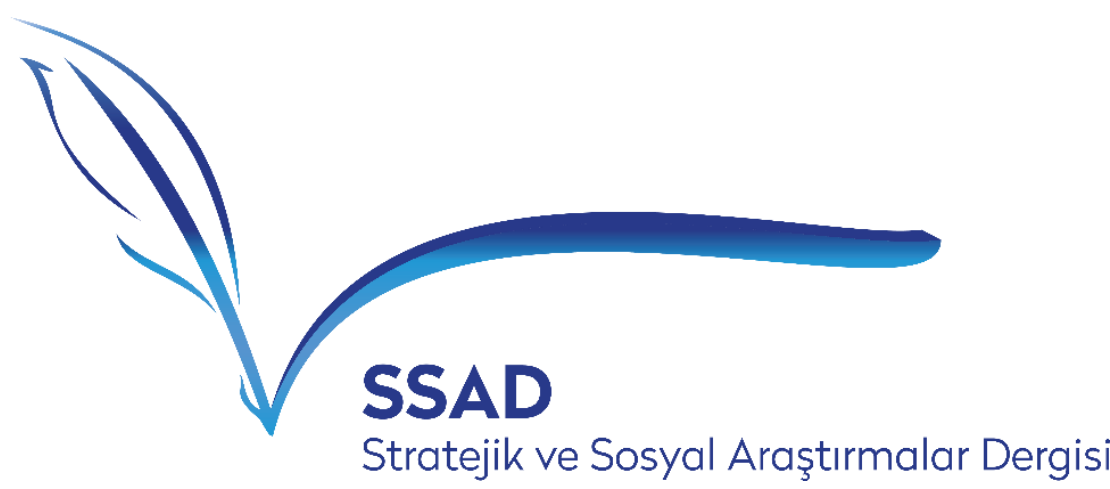

ISSN: $2587-2621$

Volume 4 Issue 1, March 2020

ORCID ID: 0000-0003-0152-4458

Makale Gönderim Tarihi: 29.01.2020

Makale Kabul Tarihi: 11.03.2020

https://doi.org/10.30692/sisad.681639

\title{
EYLEM-TEMSIL DÖNGÜSÜNDE SÖZLÜ KÜLTÜR ORTAMINDAN ELEKTRONIK KÜLTÜR ORTAMINA SOMUT VE SANAL SAHNEDE BENLİĞE KARŞILAŞTIRMALI BİR BAKIŞ
}

\section{A Comparative Overview on The Representation of Self From The Oral Culture Medium to Electronic Culture Media in Tangible and Intangible Stage}

\author{
Mehmet Taner TÜRK \\ Dr. Ögretim Üyesi \\ Selçuk Üniversitesi, Edebiyat Fakültesi, Karşılaştırmalı Edebiyat Bölümü \\ tanerturk@selcuk.edu.tr

\section{Azem SEVİNDÍK} \\ Dr. Öğretim $\ddot{U}$ yesi \\ Selçuk Üniversitesi, Edebiyat Fakültesi, Karşılaştırmalı Edebiyat Bölümü \\ azem_svndk@hotmail.com
}

\begin{abstract}
Özet: Sözlü kültür ortamı mahsulleri olan mit ve efsanelerin birer ardılları olarak ortaya çıkan tragedya ve komedyalar, yazılı kültür ortamının ürünleri olarak görülebilir. Bu oluşumun kanıtları, aynı zamanda teknolojik kodlar olarak da adlandırılabilecek yazıyı kullanmayan toplumlarda bu türlerin sanatsal bir biçimde ortaya çıkmamasında aranabilir. Sözlü kültür toplumlarında tragedya ve komedyaların yerini ritüel kökenli oyunlar ve diğer sözlü kültür mahsulleri almıştır. Yazılı kültür sadece sözlü kültür ortamında insanların kutsalları için tertipledikleri şölenlerdeki ritüellerin sahnelenmiş hali olan tragedya ve komedyaların ortaya çıkmasını sağlamakla kalmamış, aynı zamanda felsefi düşünce sistemlerinin güçlenmesini de sağlamıştır. Felsefenin ortaya çıkması ve sanatsal dramatik oyunların icra edilmesi sözlü kültür ve yazılı kültür ortamının farklılıklarının birer görünümleridir.
\end{abstract}


Her oyun bir sahneye ihtiyaç duyar. Antik Yunan'da dekor, zaman ve özel mekânlarla birlikte özgün bir sahnenin geliştirildiği söylenebilir. Bununla birlikte somut ve soyut görünümleriyle günümüzde de sahnelerin çeşitlendiği anlaşılmaktadır. Bir sahne olarak görülebilecek sosyokültürel ortamlarda oluşan sosyal kimlik; dişsallaştırma, içselleştirme, nesnelleştirme ve kurumsallaşma olmak üzere dört aşamayla meydana gelir. Kimliği oluşturan alt yapılardan birisi olan benliğin bu sosyalizasyon süreci modernite tarafindan standartlaştırılır. Elektronik kültür ortamında ise sözlü kültürün oluşturduğu ilkel benliğin yeniden canlandığı göze çarpmaktadır.

Sözlü kültürde benlik özneldir. Kimlik ise nesneldir. Yazılı kültürle beraber sözlü kültürün oluşturduğu öznel olan, doğaya ve kültüre hükmetmeyi amaçlayan ilkel benlik toplumsallaşmayla beraber nesnelleşmiş ve kurumsallaşmıştır. Bunun sonucunda "süperego" "id”i baskıllamıştır.

Bu çalışmada sözlü, yazılı ve elektronik kültür ortamındaki somut ve sanal sahnede benliğin temsilinin farklılıklarına ve benzerliklerine odaklanılacaktır. Sonuç olarak elektronik kültür ortamında ilkel benliğin; sosyal medya, spor müsabakaları, mitingler ya da konserler gibi kitlesel gösteri ve performanslarda yeniden belirdiği saptanmıştır.

Anahtar kelimeler: Benlik, Kimlik, Oyun, Sosyal Medya, Tiyatro

\begin{abstract}
The tragedies and comedies that emerged as successors of myths and legends, which are oral culture media products, can be seen as the products of the written cultural context. Evidence of this formation can also be sought in the absence of artistic expression of these species in societies that do not use the so-called technological codes. In oral culture societies, tragedies and comedies were replaced by ritual-based plays and other oral culture products. Written culture has not only provided the emergence of tragedies and comedies, staged in the rituals of the feasts organized for the saints of the people but also strengthened the philosophical thought systems in the oral culture context. The emergence of philosophy and the execution of artistic dramatic plays are the views of the differences between oral and written culture.
\end{abstract}

Every game needs a scene. It can be said that a unique scene in Ancient Greece is developed with decor, time and special places. However, with the tangible and intangible views, it is understood that the scenes are now being diversified. Social identity in sociocultural context that can be seen as a scene; is occurred as externalization, internalization, objectification and institutionalization. This socialization process of the self, one of the sub-structures constituting the identity, is standardized by modernity. In the electronic culture context, The revival of the primitive self which is created by oral culture is seen.

In oral culture, the self is subjective but identity is objective. The primitive self, occurred by oral culture with the written culture and being subjective and aiming to dominate nature and culture, is objectified and institutionalized along with the socialization. As a result, "superego" suppressed the "id".

In this study, it will be focused on the differences and similarities of the representation of the self in tangible and intangible scene in the oral, written and electronic culture context. As a result; it is detected that primitive self is appeared in mass demonstrations and performances such as social media, sports competitions, mass meetings or concerts.

Keywords: Self, Identity, Game, Social Media, Theater

\title{
GíRiş
}

Günümüz toplumları postmodern, endüstri sonrası ya da geç modern toplumlar olarak adlandırılmaktadır. Çağımız toplumlarının çoğunun gündelik hayatında gerçekleşen sosyokültürel değişimlere bağlı olarak farklı ortamlarda ilkelliğin tekrar ortaya çıktığı görülmektedir. Araştırmamızda "ilkel" kelimesi kesinlikle düşünce olarak geriliği değil ruhsal yapının ilk ortaya çıkan unsuru olan "id"in yönlendirdiği beden odaklı dönemsel davranış kalıplarını içermektedir.

Modernitenin katı kuralları ile birlikte bastırılmaya çalışılan "id"in yönlendirdiği ilkel davranışlar otoritenin zayıfladığı yani "süperego"nun ortadan kalktığı mecralarda tekrar gün yüzüne çıkmaktadır. Özellikle kamusal alanda içindeki ilkelliği bastırmaya çalışan insanlar, kitlesel hareketlerin icra edilmesine imkân tanıyan ortamlarda ya da denetimin olmadığı alanlarda otoritenin istemediği hareketleri sergileyerek bir tür arınma ritüeli gerçekleştirmektedir. Stadyumlar, konser alanları, sosyal medya, ev ya da 1ssız ortamlar gibi özel alanlar ilkelliğin yeniden gün yüzüne çıtığı alanlardır.

Gözlemci topluluğu karşısında sınırlı bir süre içinde gerçekleşen ve gözlemciyi belli açılardan etkilemeyi amaçlayan faaliyetler için kullanılan performans, belirli standartlar içeren bir ortamda icra edilir (Goffman, 2014: 33). Vitrin olarak da tanımlanabilecek bu ortamın somut ve soyut 
olmak üzere iki boyutu vardır. Dekor ya da set vitrinin somut; dijital çağın gösterge araçları olan Twitter, Facebook, Instagram vb. sosyal medya platformları ise vitrinin soyut ya da sanal yönüne işaret etmektedir.

Bir tiyatro sahnesi olarak da görülen dünyada, kişiler yüzlerine taktıkları maskelerle farklı performanslar sergileyerek bir şovmen gibi farklı rollere bürünmektedirler (Goffman, 2014). Şovmen, "kontrol altında tutmak istediği hedef kitleyi etkilemek, tarzıyla farkındalık yaratmak ister. Kendine has tarz oluşturabilmek, kimlik kazanmayı ve markalaşmayı beraberinde getirir" (Eker, 2014: 225). Sadece sosyal medya fenomenleri değil sosyal medyadaki kullanıcıların neredeyse tamamı bu eğilim içerisindedir.

Çalışma, sözlü kültür sonrasında ortaya çıkan tragedyalardaki temsil öğesinin nasıl dönüşerek melez kültür ortamı olarak da kabul edilebilecek elektronik kültür ortamında kendisini nasıl yeniden sözlü kültüre ait eylemsellikle ifade ettiğini ispatlamayı amaçlamaktadır. Çalışmamızın anlaşılması ve analitik bir ilerleme sergilemesi için benlik, oyun, tiyatro, kimlik ve maske gibi kavramların birbirleriyle ilişkisinin kurulması gerekmektedir. Bu nedenle öncelikli olarak adı geçen bu kavramlar açıklığa kavuşturulduktan sonra benlik çatışmasının ilkellikle ve uygarlıkla ilişkisi ortaya konulmaya çalışılmıştır.

Çalışmanın birinci bölümünde benlik sadece kavramsal düzeyde ele alınacaktır. İkinci bölümünde oyun ve tiyatro ilişkisi, üçüncü bölümde ise oyun kavramının psikolojik ve sosyolojik boyutları ele alınmaya çalışılacaktır. Dördüncü bölümde ise benliğin diğer kavramlarla ilişkisi üzerinden dijital ortamdaki eylem ve temsil durumu gözler önüne serilmeye çalışlacaktır.

Elektronik kültür ortamı gözlemleri ve alandaki literatür çalışmalarının taranması yoluyla (gözlemle veri toplama tekniği) oluşturulmuş çalışmamız sözlü-yazılı ve elektronik kültür ortamlarındaki insan davranışlarını karşılaştırmalı olarak ele alarak insanlık tarihindeki eylemtemsil döngüsünü gözler önüne sermeyi amaçlamaktadır.

\section{Benlik}

Günlük yaşamımızda bazı kavramları üzerinde hiç düşünmeden kullanırız. Bizi derinden sarsan ya da ani bir değişikliğin yaşandığı anlarda ise onları fark ederiz. Buna en güzel örnek olarak benlik kavramı gösterilebilir. Birçoğumuz için benlik tanımlaması oldukça zor bir kavramdır; fakat hiç kimse de kavramın varlığından şüphe duymaz. Günümüz Batı'sında benlik kavramı oldukça geç sayılabilecek bir zaman diliminde ortaya çıkmıştır. Sorgulamadan kabul ettiğimiz insanlık düşüncesinin gelişmesi okuma-yazma faaliyetleri sayesindedir. Benlik okuryazarlık neticesinde belirginleşen bir kavram olarak çağımız kültüründe kaybolma tehlikesiyle karş1 karşıyadır (Sanders, 2013, s. 9-10). Çünkü sözlü kültürün etkisini yitirmesi toplumsal etkileşimi azaltmaktadır. Diyalog yerini monoloğa bıraktığı için soyut düşünce üretimi etkinliğini yitirmektedir. Biz duygusunun yerini ben duygusuna bırakması azalan toplumsal etkileşim nedeniyle gerçekleşmektedir.

Gündelik hayatımızda bir kişinin yaptıkları ve söylediklerinin aslında kastettiğinden farklı olduğuna sıkça rastlarız. Benliğin gündelik hayatımızda yaşadığımız olaylarda ne kadarının iletişime dâhil olacağını toplumsal deneyim belirler. Diyaloga girdiğimiz her insanla farklı ilişkiler sürdürürüz. Karşıdaki kişiyi ne kadar tanıdığımız benliğimizi nasıl kullanacağımızı da belirler. Toplumsal ilişkiler sonucunda farklı farklı benlikler ortaya çıkar. Kendimizi ait hissettiğimiz toplumsal ilişkilerde birleşik benlik bulunurken, bazı eylemleri gerçekleştirmek için benlikte bölünme söz konusudur. İşte "sosyal ben" ile "ferdi ben" adı verilen iki farklı benlik bu durumlarda oluşur (Mead, 2017, s. 171). Sahnelerin bütüncül ve kapsayıcı adı olan sosyo-kültürel ortam "sosyal ben" ve "ferdi ben"i şekillendirir.

İnsanlar, bebeklik döneminde diğer insanlara yetişkinlik dönemlerinin aksine daha az önem verirler. Yaş ilerledikçe neye benzedikleri ya da hangi davranışlarının iyi ya da kötü olarak nitelendirilebileceğine dair fikir sahibi olurlar; fakat bu düşünceyi oluşturan en önemli faktörlerden bir tanesi diğer insanların o kişiyi nasıl gördüğüdür. 1902 yılı gibi erken bir tarihte 
Charles Cooley, ayna benlik kavramını kullanmıștır. Bu kavramla Cooley, kendimizi başkalarının gözünde yaşadığımızı kastetmektedir (Hayes, 2011, s. 20). Sürekli değişim ve gelişim gösteren benlik, insanın doğuştan sahip olduğu bir şey değildir. Toplumsallaşma süreci sonunda diğer bireylerle etkileşimi sonucunda ortaya çikan bir olgudur (Mead, 2017, s.165). Bu etkileşim de aslında yanlı ve korumalı bir etkileşimdir:

\footnotetext{
Benlik denildiğinde bütün toplumsal formasyonlar için belli sabiteleri olan ve bütün toplumsal formasyonlar için değişmeyen evrensel kategorilere sahip bir niteliğe değil; tam tersine belli bir toplumsal formasyonla kazanılmış, hatta yeniden üretilmiş, tanımlanmış bir kimliğe atıfta bulunmuş oluyoruz (Topçuoğlu, 1995, s. 127).
}

Benlik toplumla girdiği etkileşim sonucunda şekillenir. Ait olunan toplumun kültürel bileşenleriyle belirli bir forma ulaşan benlik aslında kimlikten ayrı düşünülemez. Örneğin, ilkel toplumlarda bile bireyin kimliği, topluluğun ona verdiği değerle şekillenir ve böylece birey yeni bir statü kazanır. Oğuz Kağan Destanı'ndan da hatırlayacağımız Oğuz Kağan'ın avlanamayan ve öldürülemeyen gergedanı alt etmesi (Çobanoğlu, 2007, s. 124), Dirse Han oğlu Boğaç Han boyunda Boğaç Han'ın bu adı boğaya üstünlük sağlayarak alması (Ergin 2011: 78), Robin Hood ve Köroğlu'nun soylu sınıf karşısındaki mücadeleleri sonrasında kahraman statüsüne ulaşması vb. bu duruma örnek olarak gösterilebilir. Kahramanlık statüsüne ulaşmak, ait olunan grubun ya da topluluğun onayıyla gerçekleşir. Bir başka ifade ile, içinde yaşadığı grubun çıkarlarına uygun bir hareketin gerçekleşmesi gerekmektedir. Böyle bir durumda karşı tarafı düşman ya da öteki olarak yaftalamak zorundadır.

Yukarıda sayılan örneklerin hepsinde bedensel eylemler görünmektedir. Benlik ve beden birbirinden ayrı düşünülür; fakat bedensel hareketleri benlik düzenler (Mead, 2017, s. 166). Descartes, "düşünüyorum öyleyse varım" önermesinde akla vurgu yaparak bedeni sadece uzamda yer alan mekanik bir yapı olarak ele alır. Beden, kartezyen anlayışla dış dünyaya aitken akıl düşünen şeydir. Beden sadece aklın komutlarıyla hareket edebilen bir makinedir (Işık, 1998, s. 200-201). Bedensel hareketlerin onayı toplumda hâkim olan kimliğin onaylanması ile gerçekleşir.

Aydınlanma döneminde akıl ve beden birbirinden ayrı düşünülmüştür. Çünkü bedenin rasyonel hareketleri yapması için kontrolünün akıl tarafindan yapılması gerektiği düşünülmüştür. Uygarlığın ve kültürün ilkellikten medeniyete doğru tek bir hatta ilerlediğini düşünen evrimci anlayışın temsilcileri ve ardılları, bedeni ya da başka bir ifadeyle bedenin ifade biçimi olan hazzı ötekileştirmiş̧ir. Postmodern dönemde ise Aydınlanma dönemindeki düşünce yapısının aksine, beden akıl tarafından kontrol edilemez bir yapıya bürünmüştür. İhtiyaçların haz ya da arzu olarak karşımıza çıkartıldığı postmodernizm yeni benlik tasarımlarının seri üretime geçtiği dijital kültür ortamında kendisini göstermektedir.

Radyo ve televizyon kendi geleneklerini oluşturarak yeni oyuncu tiplerini iletişimin farklı bir boyutuyla sahneye yerleştirmiştir. Bu sahnede eylemi gerçekleştiren kişilere sınırları belli olan roller biçilmiştir ve bu roller hiç olmadığı kadar katıdır. Böylece aklın beden üzerindeki otoritesi devam etmiştir. Bilgisayar ve devamında karşımıza çıkan internet sayesinde aklın yüklediği ödevlerden sıyrılan beden, yeni bir toplumsallaşma türünün görüldügü sosyal medya platformlarında yeniden üretilen benlikle özgürlüğüne kavuşmuştur. Sanal bir toplumsallaşma ile oluşan benlik bireye kuralları esnek olan bir oyunun parçası olma şansını tanımıştır. $\mathrm{Bu}$ platformların katılımcı bireylerden istediği tek bir şey vardır; oyuncu olmak.

\section{Oyun ve Tiyatro}

Mağaradan dijital çağa giden yolda insan davranışlarına yön veren benlik ve maske kavramlarının daha anlaşılır kılınması için tarihsel perspektifte oyun ve tiyatro meselesinin detaylı bir biçimde ele alınmas1 gerekir.

Dünya oyun sahnesi ve tüm canlılar/insanlar oyuncudur (Nutku, 2011, s. 20). Oyun dinî-ritüelistik uygulamalarda, kutsal ve gerçek kabul edilen mitolojide (şaman olma ve büyü bozma ritüelleri), doğum/askerlik/evlilik gibi geçiş törenlerinde, bağ bozumu veya bolluk-bereket törenlerinde (ki komedyalar ve tragedyaların oluşumundaki esas etmen bu törenler ve yazılı kültürdür; o halde 
modern tiyatro oyunlarının kökeninde de arınma/katharsis aranmalıdır), eğlence kültüründe oyun kendisini gösterir. Antik Yunan'da tiyatro oyunlarında ilkel dönemin büyü ve sihir anlayışı yerini çağdaş düşünce yapısına bırakarak taklidin tiyatroda bir değer haline gelmesini sağlamıştır (Şener, 2016, s. 16). Oyun kültürden farklı bir kavramdır. Çünkü oyunu oynamak için insan olmaya gerek yoktur. Kültür ise insani faaliyetler bütününe işaret eder. Tiyatronun kökenindeki insanın hayvanları taklit etme eylemi aslında oyundan tiyatroya mirastır. Bu süreci Huizinga şu sözlerle özetlemektedir:

\begin{abstract}
[...] "oyunun" daha da "içinde" olan ve aydınlatılması çok güç bir ruhani unsurla karşılaşırız. Kutsal temsil bir görünüşün gerçekleştirilmesinden daha fazla bir şey olduğu gibi, simgesel bir gerçekleştirmeden de fazla bir şeydir: Mistik bir gerçekleştirmedir. Görünmez ve sözle anlatılması olanaksız bir şey burada güzel, hakiki ve kutsal bir biçime bürünmektedir. İbadete katılanlar, eylemin yüce bir mutluluğu somutlaştırdığından ve kendi alışılmış hayatlarındakinden daha yüksek bir düzeni gerçekleştirdiğinden emindir. Ancak, bu gösteri yoluyla gerçekleştirme, gene de oyunun biçimsel karakteristiklerini her açıdan korumaktadır. Eyleme bağlı olarak sınırları belirlenen bir mekânın içinde sahneye konulmakta ve bir şenlik gibi, yani neşe ve özgürlük içinde oynanmaktadır. Geçici bir değeri olan, kendine özgü bir evrenin sınırları bu amaçla belirlenmektedir. Ancak bu gerçekleştirmenin etkisi oyunun bitmesiyle sona ermez: Görkemini dışarıya, olağan dünyaya yansıtmakta ve bayramı kutlamıș olan grup için, bir dahaki kutsal dönem gelene kadar güvenlik, düzen ve refah sağlamaktadır. Dünyanın her bir köşesinde buna benzeyen örnekler bulunabilir. Eski bir Çin doktrinine göre, dans ile müziğin amacı evreni kendi yolunda tutmak ve doğayı insana yararlı olmaya zorlamaktır. O yılın refahı, mevsimleri karşılayan şenliklerde düzenlenen müsabakalara bağlıdır. Eğer bu toplantılar yapılmazsa, ürünler olgunlaşamayacaklardır (Huizinga, 2006, s. 32-33).
\end{abstract}

Kültür tanımlarına bakıldığında ister betimleme ister yorumlama isterse de değerlendirme biçiminde yapılsın, hepsinde karşımıza insani faaliyetler çıkar. Planlı ve programlı bir hareketi içeren kültürün aksine oyun mistik ve gizemli bir doğaya sahiptir. Katılımcıların hareketlerini daha duygusal temellerle gerçekleştirdikleri görülür. Ayrıca her ne kadar bir kural içerse de oyunun kuralları kültür gibi ilerlemeci bir anlayışla kurulmaz.

Oyun kavramının içeriğine kısa bir bakıştan sonra etimolojik kökenine bakıldığında Metin And'a göre (2012, s. 37-38) (y) kaynaştırma harfiyle birleşen "o-" fiilinin "ot" (=ot, ilaç) biçimi, oyun kelimesinin etimolojik kökeninin temelini oluşturduğu görülmektedir. Divanü Lügati’t-Türk üzerine yapılan bazı çalışmalarda da "ot" kelimesi "ilaç, em; zehir" ve "ot-çı" "hekim, ilaç yapan" (Atalay, 1943, s. 444) şeklinde tanımlanmıştır. Bu anlamda oyun kelimesine kaynaklık eden "ot", şamanların hastalık yaratan kötü ruhlarla savaşlarında kullandıkları "ilaç"tan türemiştir. Oyun kelimesinin anlamlarına bakıldığında, birçoğunda Şamanizm unsurları akla gelmektedir. Şaman; şölen ve törenlerde dans eder, çalg1 aleti çalar, çeşitli sesler çıkararak taklit yapar ve şiir okur. Tiyatro, dans ve diğer seyirlik oyunların kökenlerinin şamanda ve şamanın eylemlerinde toplandığ görülmektedir (And, 2012, s. 37). Orta Asya'da şamanlara "oyun” denilmesi de bu açıdan önemlidir.

Abdülkadir İnan, Yakutlar ve Doğu Türkistan Türklerinin "kullandığı araçlar (cübbe, külah, davul, taş, put-fetişler) ve yöntemlerden (ayinlerdeki dans ve dramatik gösteriler, dua, ilahi ve efsunlar) yararlanarak günlük yaşamdan farklı bir dünyada hareket eden" (Aktaran: Özdemir, 2005, s. 207) erkek şamana "oyun" dediklerini, Saha ve Yakut Türkleri arasında bugün bile şamana "oyun" adı verildiğini belirtir (İnan, 1976, s.74). Günümüzde Anadolu'da oynanan köy seyirlik oyunlarının çağdaş tiyatronun temellerini attı̆ğ söylenebilir. Oyun ve seyircinin bir bütün halinde hareket ettiği köy seyirlik oyunları, gündelik olaylara (profan mahiyette) da yer vermesine rağmen, pagan/şaman törenlerine ait unsurlar kendisine yer edinmeye devam eder. Her ne kadar güldürü unsurları barındırsa da oyunlar dinsel kökenden kaynaklı bir ciddiyet de barındırır (Şener, 2011, s. 7). Yunan tiyatrosunda olduğu gibi Anadolu'da da ilkel ritüellerin çağdaş düşünce yapısıyla ele alınarak taklit unsuruyla sanatsal hale geldiği görülür.

Oyunun kaynaklarından bir tanesi de avlanmadır. İlkel insanların av oyunlarında tiyatronun üç temel ilkesi göze çarpar: taklit, eylem ve topluca kat1lım. İlkel oyunlarda oyuncular önceleri ellerini çırparak ya da ayaklarını yere vurarak bir ayin gerçekleştirir, sonradan söz konusu bu oyuna ezgiler ve belli anlamlara gelen sesleri eklerler. Bu oyunlar av törenlerinden doğa güçlerine olan saygıyla karışık korkuya kadar bir gelişme düzeyi gösterir. Böylece kutsal kabul edilen 
yağmur duaları, bolluk törenleri, ölüm-dirilme oyunları ortaya çıkar. Avcı avını avlayabilmek için önce bir hayvan postuna bürünür ve hayvanın hareketlerini taklit ederek yakınına girer, avını öldürür, sonra köyüne döner, nasıl avladığını ötekilerine anlatacak bir hareketler düzenine girer. Bu ise eylemdir. Dans, ezgi ve hareketle oyununu sürdüren avcıya karşı seyirciler de avın uğurlu olmasını sağlamak için dans ederler. Bu da topluca katılımdır (Nutku, 2011, s. 17). Taklit, eylem ve topluca katılım gibi tiyatronun temel ilkelerinin kökenini doğada ya da başka bir ifade ile oyunda buluruz. Kültürel bir form olan tiyatroya eklemlenen bu ilkeler uygarlık sürecinde ilkelliğin her zaman varlığını sürdürdüğünü göstermesi açısından önemlidir. Tiyatro-oyun ilişkisinin daha net olarak anlaşılması için tiyatro türlerine yakından bakmak gerekli olabilir.

Tragedya, Yunanca tragoidia'dan gelir; tragos (keçi) ve oidie (türkü) sözcüklerinin birleşmesiyle keçilerin türküsü anlamında kullanılır. Dionysos şenliklerinde koro, tanrının ona bağlı kölelerini simgeler. Tanrının çevresinde hep doğanın yabancı güçlerini temsil eden teke ayaklı satirler bulunduğu için ilk bakıșta koro da satirlerin biçimine girmiștir; ilk dönemlerde korodaki oyuncular teke derileri (tragoi) giyerek oyun alanına çıkmışlardır. Tragedya türü de tragos'ların şarkılarından doğmuştur (Nutku, 2011, s. 33). Dionysos şenliklerinde söylenen dithirambos şarkıları ile ortaya çıkan tragedya dinsel bir tören olarak ortaya çıksa da sonraları bir "sanat gösterisi"ne evrilmiştir (Şener, 2016, s.16). Antal Szerb, Dionysos'u devrimci bir tanrı olarak değerlendirir. Gençlerin ve kadınların tanrısı olarak görülen Dionysos, akıldışı güçlerin özgürleşmesi anlamına gelirken, sınırsız tutkunun ve acının temsilcisi olarak Helen kültüründe kendisine yer edinmiştir. Dans ve koroyu kısa zamanda hizmetine alan Dionysos için sanata karş1 büyük bir ilgisi bulunan tiran Periandros şölenler örgütlemiştir. Dionyssia adı verilen bu şölenlerde dans ve koro birleşmiş ve günümüze kadar gelen süreçte sahne oyunu kurumsal bir yapıya kavuşmuştur (Szerb, 2008: 35-36). Günümüz tiyatrosunun temellerinin de bu şölenlerde atıldığı pek çok kaynak tarafından da doğrulanmaktadır. Şener (2011, s.8) Max Müller, Wilhelm Mannhardt, Andrew Tang, E. B. Taylor, William Robertson gibi bilim adamlarının isimlerini bu savı destekleyenler arasında zikretmektedir.

Mageralı oyuncular, köy köy dolaşmalarına atıfta bulunarak ve kendi dillerinde köyler anlamına gelen 'komai' kelimesini işaret ederek 'komedya' adının bu şekilde ortaya çıktığı tezini ileri sürmüşlerdir (Öngören, 1996, s. 34) diyen Aristoteles "Poetika" adlı eserinde şehirli oyuncuların köylere gitmesiyle ilişkilendirdiği komedya kelimesinin oluşumu ile ilgili daha ayrıntılı bilgiler verir. Aristoteles'e göre komedyanın törensel şarkılarla bir ilişkisi vardır; komedya "Phallos şarkılarından doğmuştur ve 'Komos Şarkısı' yahut 'Komos alayında söylenen şarkı' demektir” (Öngören, 1996, s. 34). Bir eğlence türü olan "Komos"un ilk biçimleri ise "Pompeler"dir. Yine Aristoteles eserinde epik destanlar, tragedya, drama ve komedya ile ilgili dikkat çekici bilgiler verir:

(...) Şimdi destan (epopoiia) ve tragedya şiiri, ayrıca komedya, dithyrambos şiiri ve aulos ile kithara sanatlarının hepsi ana hatlarıyla öyle ya da böyle taklittir (mimesis). Ancak bunlar taklit ederken kullandıkları araçlar, taklit ettikleri nesneler ve taklidi aynı şekilde değil de farklı bir tarzda yapmaları itibarıyla üç bakımdan birbirlerinden ayrılırlar. (...) Tragedya komedyadan bu farkla ayrılır: İkincisi günümüz insanlarından daha kötüleri, ilki daha iyileri taklit etmek ister. (...) Sophokles bir anlamda Homeros'la aynı türden bir taklitçidir, zira ikisi de ağırlığı olan kişileri taklit ederler; öte yandan Sophokles Aristophanes'le de aynı türden bir taklitçi sayılabilir, zira ikisi de taklidi eylem ve davranışlarda bulunan insanlarla gerçekleştirirler. Zaten kimilerine göre bu tür eserlere drama (dramata) denmesinin nedeni, davranışlarda bulunanları taklit etmeleridir. Dorlar tragedyayı da komedyayı da bu yüzden kendilerine mal ederler ve bunun göstergesi olarak sözcüklere başvururlar: Kentleri çevreleyen yerleşimlere kendileri kôme derken Atinalıların demos dediğini, "komedyen (kômôidos) sözcügünün de zaten "cümbüş yapmak" (komazein) fiilinden değil, bu insanların aşağılanarak kentten kovulup bir kômeden diğerine dolaşmalarından geldiğini söylerler; "yapmak" için Atinalıların pratteini kendilerininse dranı kullandığını da söylerler. (...) Tragedyalar için İlyada'yla Odysseia neyse komedyalar için de Margites odur. (...) Komedya daha bayağı insanların taklididir ama kötülüğün her türünü ele almaz, gülünç olanı, yani çirkinliğin belli bir kısmını ele alır. Çünkü gülünç olan, insana rahatsızlık vermeyen bir kusur ve çirkinliktir. Örneğin gülünç maskeler çirkin ve çarpık olur ama insanı rahatsız etmez. Tragedyanın gelişim aşamaları ve bunları borçlu olduğumuz kişiler hakkında bilgi yok değil ama komedya ciddiye alınmadığı için baştan beri unutulmuş. Komedya ozanı denen kişiler ancak komedya belli bir biçim kazandıktan sonra hatırlanır oldu. Maskeleri, ilk sözleri (prologos) ve birden fazla oyuncuyu ilk kimin kullandığı, kaç oyuncu kullandığı bilinmez olmuş (Aristoteles, 2017, s. 1- 
14).

Geçen zaman içinde tragedyada Dionyos ile ilgili öğelerin azaldığı görülür. Bu unsurları artırmak için birkaç yüzyıl sonra satirik drama denilen tragedya ile komedya arasında konumlandırılabilecek yeni bir tür ortaya çıkar (Tekin, 1998: 124).

Tiyatro; dram ve oyunun bileşimidir. Dram; akış halinde olan yaşamın olduğu gibi icra edilmesi ve canlandırılmasıdır. Dramlar sahnede oynanmak için yazılırlar. Biçim olarak karşıtlıkların çatışmasıyla gelişen ve başkaları önünde bir eylemin canlandırıldığı oyunlardır. Dramlar tragedya ve komedya şeklinde ikiye ayrılırlar. Dram kavramıysa, Eski Yunan dramı bağlamında tanımlanır. Batı tiyatrosu bu kaynaktan beslendiği için tanımlamalarını da ona göre oluşturur. Bizim kendimize özgü bir dramımız yoktur. Kaldı ki başta dil bakımından Eski Yunan'ın Hıristiyan mirasçısı Bizans İmparatorluğu bile bin yıllık ömründe özgün bir dram yaratmak şöyle dursun, Antik Yunan örneğinde bir dram bile geliştirememiştir. Avrupa'nın dahi Ortaçağ'da yarattığı Hıristiyan dramı Antik Yunan kaynaklıdır. İslam dininde de dramın oluşturulamadığ 1 göze çarpar. Yalnızca Hıristiyanlıkta acı çekme (passion) oyunlarının bir benzeri Şiî inancı taziyelerinde, Kerbela olaylarının sergilenmesinde bir nebze göze çarpar. Türk tiyatrosunun dram yokluğu bir kenara bırakılıp oyunculuk gibi seyirlik yanına döndüğümüz zaman geleneksel Türk tiyatrosu başlığı altında incelenen bu yüzün özgün bir tiyatro niteliği taşıdığg görülür. Türk tavrı ve üslubu bu tiyatrolarda hemen fark edilir (And, 1983, s. 5-6).

Dramatik tiyatronun kaynağında büyü, gösteriyi ortaya çıkaran bir araçtır. Büyü, maske ve dansla gelişen oyun, insanoğlunun doğaya karşı durmasına yaradığı kadar insanlar arasındaki duygusal bağların gelişmesine de yol açar. Ancak tiyatronun kaynağını yalnız bu özelliği ile açıklamak eksik kalır. O halde tiyatronun kaynağı nedir? Büyü kadar doğada insanları çeken renkler, etkili kokular, göz alıcı biçimler, güzel sesler ve hareketler tiyatronun doğuşunda etkindir. Tartımlı düzen de tiyatronun kaynağıdır ve bu düzen doğada da vardır; yüreğin atışı, solunum, cinsel birleşme, başka deyişle birtakım özelliklerin tartımlı tekrarı ve bundan insanların aldığ 1 tat, tiyatronun kaynağındaki dans, jest, ezgi ve maske ile bütünlüğe erer (Nutku, 2011, s. 18). İlkel büyü törenleri, tıpkı tiyatro gibi, belirli bir düzen içermelidir. Kutsal törenler, her ne kadar içerik olarak büyü içerse de, biçim bakımından teatral ya da daha kesin ifadeyle dramatiktir. Örneğin; Osiris, Attis, Thammuz, Adonis, Dionysis, Demeter vb. mitlerde yaygın biçimde görülen ölme ve diriltme olayının temsillerinde biçimsel olarak taklidin bir düzen içinde gerçekleşmesi beklenir.

\section{Oyun, Kimlik ve Maske}

Fizyoloji, psikoloji ve sosyoloji; hayvanların, çocukların ve yetişkin insanların oynadıkları oyunu gözleyen, betimleyen ve yorumlayan ve neticesinde onun hayat düzlemindeki yerini saptamaya çalışan bilim dallarıdır. Bu bilim dallarında araştırma yapanların bir kısmı oyunu biriken yaşam enerjisi fazlalığından kurtulma ya da gevşeme; bir kısmı egemenlik kurma; bir kısmı zararlı eğilimlerden kurtulma; bir kısmı gerçek hayatta gerçekleştirilmesi mümkün olmayan arzuların kurmaca bir ortam vasitasıyla giderilmesi ve böylece benlik duygusunun korunması olarak görmektedirler. Oyun hangi açıdan ele alınırsa alınsın cevabının bulunamadığı bir şey vardır. Oyunun zevkli bir yanı (aardigheid) vardır. İster yavru köpeklerin, bebeklerin oyunu olsun, ister bir futbol maçında bağıran kitleler olsun durum ve bağlam değişmez. Kelime anlamı doğa olan "aard" kelimesi bizi kültürün tam karşısına çıkarmaktadır (Huizinga, 2006, s. 18-19). İnsanın sahip olduğu ferdi ve sosyal benlik arasında yaptığı geçişlerde kullandığ1 araç maske olarak nitelenebilir. Şartlara göre insanın takındığı tavır ve sergilediği hareket ve davranış kalıplarına yön veren soyut maskelerdir. Burada kastedilen Dionysos şenliklerinde insanların taktığı somut maske değildir. Maske yukarıda sözü geçen rahatlama, gevşeme ya da benliğin korunmasında aracilik etmektedir.

Öyleyse, insanlar neden maske takarlar? Bunun iki sebebi vardır. Birincisi, maske tanıdığımız kişiyi yok eder ve onun insana özgü yüzünü ve ifadesini alarak yerine tanımadığımız, doğaüstü, insanla ilgili olmayan bir görünüş içine sokar. İkincisi, maske, oyuncunun yüzünü yeniler ve ona bir özellik verir. Bununla birlikte iki çeşit maske vardır. Biri, yüzün boyanmasıyla ten üzerinden yapılan maskedir. Diğeri, yabancı bir maddeden (tahta, bakır, ot, tüy, alçı, tutkal kâğıt hamuru 
vb.) yapılan ve istenilen ifadenin daha kolayca verilebildiği maskedir (Nutku, 2011, s. 18). Yukarıda sözü edilen somut maskelerin yanı sıra maskenin az önce kısmen değinilen bir de soyut boyutu bulunmaktadır. Kişinin kendi kimliğine ya da kimliğin belirlediği role inanmadığ durumlarda ortaya çıkardığı yeni kimlik de bir maskedir. Ezra Park bu durumu şu sözlerle ifade etmektedir:

\begin{abstract}
Kişi (person) sözcüğünün ilk anlamının "maske" olması büyük olasıllkla basit bir tarihsel rastlantı değildir. Daha ziyade herkesin her zaman ve her yerde, az çok farkında olarak belli bir rolü oynadığ gerçeğinin kabulüdür bu. ... Biz birbirimizi bu roller içinde tanırız; bu rollerde kendimizi tanırız. Bir anlamda, kendimiz hakkında oluşturduğumuz anlayışı-hakkını vermeye çalıştı̆̆ımız rolü-temsil ettiği sürece bu maske bizim daha hakiki benliğimizdir, olmak istediğimiz halimizdir. Sonuçta, rolümüzü anlayış şeklimiz doğamızın, kişiliğimizin ayrılmaz bir parçası haline gelir (Park, 1950, s. 249-250; Aktaran: Goffman, 2014, s. 31).
\end{abstract}

Mikhail Bakhtin, François Rabelais ve Ortaçağ-Rönesans Halk Kültürü adlı kitabının resmi bayram ile karnavallarda insan davranışlarını karşılaştırdığı bölümünde bu tarz bayramların halkın genellikle kendi fikirlerine uymayan; fakat değişmez olarak kabul edilen normları, yasakları ya da dini ya da politik değerleri dayattığını, bununla birlikte karnavallarda kast, mülkiyet, aile ya da yetişme tarzı gibi bütün hiyerarşik düzenin tamamen ortadan kalktığ 1 -yani eşitliği kutsadığını- belirtmektedir (Bakhtin, 2016, s.18-19). Gerçekliğin grotesk bir sunumu olan karnavallarda özellikle devlet ve kilise yetkilileri halk tarafından yoğun olarak alaya alınır ve toplum önünde küçük düşürülür. Senenin belirli dönemlerinde de olsa halk ve otorite sahipleri konum değiştirir. Böylece gerçeklik algısı karnavallar sayesinde groteskleşir. Gerçeklik ters yüz edilerek gündelik hayatın gerçeğinin yerini karnavalın sunduğu grotesk gerçeklik alır (Çil, 2017, s. 81). Gerçeklik algısının groteskleşmesinde maske anahtar role sahiptir. Çünkü yan yana gelmesinin gülünç durumlar oluşturduğu zitlıkların abartılı bir sunumu olan groteski takılan maskeler sağlamaktadır.

\title{
4. Eylem-Temsil Döngüsünde Sözlü Kültür Ortamından Dijital Çağ’a Somut ve Sanal Sahnede Benliğe Karşılaştırmalı Bir Bakış
}

Yazı ve matbaadan önceki dönemlerde yaşayan ve iletişimini sadece konuşma diliyle sağlayan kültürler "birincil sözlü kültür" olarak adlandırılırken günümüzde radyo, televizyon, telefon ya da diğer elektronik medya aygıtlarının sözlü nitelikleri "ikincil sözlü kültür” olarak adlandırılmaktadır. Günümüzde neredeyse bütün kültürlerde yazı ya da yazı deneyimi mevcut olduğu için birincil sözlü kültür artık yok denecek kadar azdır; fakat ikincil sözlü kültürün içinde birincil sözlü kültüre ait düşünce tarzları ve eylem ifadelerine sıkça rastlanmaktadır (Ong, 2014, s.23-24). Birincil sözlü kültüre göre oldukça denetimli bir yapıya sahip olan yazılı kültür aslında uygarlıkla eşdeğer olarak düşünebilir. İlkellik ya da barbarlık sesli ya da gürültülü; uygarlık ise sessizdir. İlkellikte eylem, uygarlıkta ise temsil vardır. Uygarlık doğanın taklidi olarak bir anlamda doğanın temsilini gerçekleştirmektedir. Günümüz dünyasında hem eylem hem de temsil bir arada yürümektedir. Tarihsel olarak sözlü kültürden yazılı kültüre geçiş; yerini artık yazılı kültürden sözlü kültüre dönüşe bırakmıştır. Bu yüzden uygarlığın sessiz hareketi olan yazılı kültür içinde sözlü kültürün eylem hareketleri kendisini göstermektedir.

Sanders'a (2013, s.11) göre okuryazarlığın temeli iyi bir sözlü kültüre sahip olmaktan geçer. Televizyon, sinema, bilgisayar vb. elektronik aygitlar sözlü kültürden yazılı kültüre giden yolu tıkamaktadır. Yine Sanders (2013, s. 34), köylülerin çarşı-pazar alışverişlerini sözlü kültürle, süpermarketlerde yapılan alışverişi ise yazılı kültürle ilişkilendirir. Köylülerin pazar alışverişlerinde hem alıcı hem de satıcı aktiftir ve canlıdır. Bu canlılıkları adeta teatral bir gösteriye de dönüşebilir. Bu yüzden yapılan pazarlıklar ya da söylemler pazarda bulunan kişilerin ilgisini çeker ve bir seyirci kitlesi meydana getirir. Burada ilgi çeken satılan mal değil alıcı ve satıcı arasında değiş-tokuşu yapılan söz ve temsil yeteneğidir. Yazılı kültürün somutlaşmış hali olan süpermarketlerde ise bir edilgenlik ve suskunluk söz konusudur. Satıcı alıcıyı ürünü alması için zorlamaz. Alıcı da ürün pahalıysa başka süpermarketlere gider (Sanders, 2013, s.14). 
Uygarlığın bir diğer göstergesi olan televizyon da aynı süpermarketler gibi alıcıyı edilgen bir hale sokar. Verilen mesajları alıcı (izleyici) karşılık veremeden içselleştirmek zorunda kalır. Bilgisayar ile birlikte elektronik kültür ortamlarında ise farklı bir yapı bulunur. Alıcı ve gönderici, aynı Sanders'ın çarşı-pazar örneğindeki gibi, canlıdır ve etkindir. Yazılı kültürün bir ürünü olan bilgisayarda ilkel olarak görülen eylemler tekrar gün yüzüne çıkmaktadır. Yazılı kültür öncesinin kime ait olduğu bilinmeyen eserlerinin yerini kime ait olduğu bilinmeyen paylaşımlar almaktadır. Bir başka ifadeyle elektronik kültür ortamında anonimlik tekrar belirginleşmiştir.

Postmodern durumun kendisini en iyi gösterdiği alanlardan bir tanesi elektronik kültürün lokomotifi konumuna ulaşan sosyal medyadır. Uygarlık ve modernlik düzen ister. Postmodernizm ise kaostan beslenir. Anlam ve eylem bulanıktır, karmaşıktır. Eylemin aktörü çoğunlukla bilinmez. Yapılan paylaşımların sahibi sahte (fake) hesaplardır. Sorumluluk duygusundan kaçışı da barındıran bu tarz eylemler aslında yeni tür bir toplumsallaşma biçimini somutlaştırması açısından önemlidir. Ortak değerlerin olmadığı bu tarz yaşam biçimi kendisine en iyi hareket alanı olarak sosyal medya ortamını seçmektedir. Çünkü sosyal medya ile somut olarak yaşadığımız dünya biçimsel olarak birbirinden çok farklıdır; fakat yapılan eylemler benzerlik taşımaktadır.

Sürekli bir işe sahip olan bir kişinin o zamana kadar yapmış olduğu işi bırakıp yepyeni bir uğraş1 sahibi olmas1, o bireyin yeni dâhil olduğu sosyal hayat neticesinde eski hayatına dair deneyimlerini yavaş yavaş arka plana atıp yeni ortama dair eylem dizgelerini benimsediği görülür. Eğer yeni ortamla aşina olduğu eski ortamın ilişkilerinde benzerlikler fazlaysa benlik bölünerek sorunsuz ya da fazla sorun yaşamadan kişinin hayatına devam etmesini sağlar. Sosyal medyada da benzer bir durum söz konusudur. Sosyal medyada bağlama bağlı olarak farklılaşan ve çeşitlenen icra performansları vardır. Arkadaş bulma sitelerinde romantik bir kimliğe bürünen birey, taraftar forum sitelerinde radikal ve ilkel bir duruş sergileyebilir. Aşama aşama arınan ve bu süreçten haz duyan benlik bireyin gündelik hayatta oluşturduğu benlikten uzaklaşır ve yeni bir benlik oluşturur. Sosyal medyada inşa edilen bu benlik, kişinin gündelik hayatta toplum nezdinde elde ettiği benlikle çatışır ve bazen de taban tabana zıtlık taşır. Maskeler kişinin gündelik hayatına dair değerlere karşı gösterdiği sapmaların gizlenmesini sağlar.

Sosyal medya ilk etapta herkese kendi karnavalına katılma imkânı sunar. Bunun için yapılması gereken belirli ritüeller vardır. Bu ritüellerin ilki gerçek kimliğin ve benliğin maskelendiği kullanıcı adlarıdır (nickname). Toplumdaki sınıf ayrımının ortadan kalktığı karnavallar gibi sosyal medyada da bireyler kullanıcı adları sayesinde doğal sosyo-kültürel ortamlarda kullandıkları maskeleri de bir kenara bırakarak özgün kimliklerini sergileme şansı elde ederler. Günlük hayatta baskıladıkları benlikleri sosyal medya aracılığıyla gün yüzüne çıkar. Bu durumu sağlayan yeni, farklı ve denetimsiz bir ortamda bulunmaktır. Sosyal medya insanlara bu şansı tanımaktadır. Böylece insanlar hayatlarını sosyal medyada paylaşılabilecek şekilde kurgulamaktadırlar. Bunun için kendilerine sürekli deneyim alanları yaratırlar. Bu deneyim alanlarındaki sunumlar ise tıpkı ilkel insanların av oyunlarındaki teatral icranın üç temel ilkesi olan taklit, eylem ve topluca katılım unsurlarını bizlere hatırlatır. Doğanın ve eylemin taklidi olan "mimesis" ve ayrıca topluca katılım ve hatırlanan deneyimler sonucunda gerçekleşen "katharsis"in temelleri bu unsurlarda aranmalidır.

Hatasız olma isteği ve diğerlerinin gözünde itibarını sürdürme arzusu grup tarafindan önceden belirlenmiş olan uygun davranışları teşvik etmektedir. Hatasız olma isteği eylem öncesinde eylemin nasıl yapılacağına karar verme; itibar kazanma ve koruma isteği ise diğerlerine karş1 yapılan davranışlar üzerinde etkide bulunur. Her iki durum da grup aidiyeti için yapılır. Grup kimliğine aykırı davranışlar olan sapmalar grup üyeleri tarafindan onanmaz ve çeşitli yaptırımlar içerir (Jenkins, 2016, s.169). Aynı sosyal ortamda bulunan kişiler benzer performans ve davranış kalıpları ile birbirlerini anlamaya çalışır. Aslında toplumsal sınıflardaki ortak beğeniler de benzer durumlarda benzer davranış kalıplarını benimsemelerinden kaynaklanır. Paylaştıkları bağlam onların grup/sınıf kimliğini meydana getirir (Yıldırım, 2019, s.18-19). Hem bireyin davranışları hem de grup ya da sınıfın yargıları birbirini etkiler. Sosyal medyadaki farklı uygulamalarda görülen beğeninin silinmesi, "retweet"in geri alınması, takipten çıkılması, "mention"ların 
silinmesi vb. sosyal medya ritüelleri gruptan dışlanmaya örnek olarak gösterilebilir. Yapılan paylaşımın destek görmesi için ya da karşıt görüş içeren bir paylaşımın tepki görmesi için grup kimliğini en iyi biçimde sunduğu düşünülen kişiler, ki çoğunlukla fenomen olarak isimlendirilen kullanıcılar, paylaşımlarda etiketlendirilir.

Grup ilkelerine tutarlı paylaşımlar yaparak gruba uymak kişinin grup kimliğini rasyonelleştiren unsurlardır. Böylece grubun kuralları içselleştirilmiş olacağından kişi itibarını korumayı sürdürecektir. Jenkins (2016), kimlik inşasının son aşaması olan kurumsallaşmayı alışkanlıklarla örtüştürerek şu cümlelerle ifade etmiştir: "Kolektif alışkanlık bir kurumsallaştırma şeklidir ve alışkanlık çoğunlukla kurumsallaşmış örüntülerin bireysel ifadesidir" (s.186). Belirli kavramlar üreterek ve bu kavramlar çerçevesinde gruplar kuran ve kendilerine karşı yine kavramlarla üretilen gruplarla mücadele etme ihtiyacı hisseden sınıflar; olaylara farklı açıdan bakarak farklı beğeni ve algılara karşı ortak davranış kalıpları belirler (Bourdieu, 2015, s. 694, 696). Faillerin yatkınlıkları, habitusları ya da sosyal dünyayı idrak ettikleri zihinsel yapılar ait oldukları sosyal yapıyı içselleştirmeleriyle mümkündür. Bu sosyal gerçekliğin inşası sadece bireysel değil aynı zamanda kolektif bir teşebbüsün de sonucu olabilir. Kısaca sosyal dünyadaki konumları üzerinden sahip oldukları bilişsel ve değerlendirici yapılar olarak habituslarına göre tahayyülleri değişkenlik gösterir (Bourdieu, 2014, s. 201).

Sosyal medyada iki türlü maske vardır. Bir tanesi bedenin diğeri ise entelektüel düzeyin farklı sunulmasını temin etmektedir. İlkinde fotoğraf filtreleme programları sayesinde yüzde bulunan kırışıklar, sivilceler, dişlerdeki lekeler vb. ortadan kaldırılır; diğerinde ise sağduyu, çalışkanlık, iyimserlik, pratik zekâ vb. durumlar ortaya konulmaktadır. Sosyal medyadaki bu tür maske kullanımı günümüz insanının yeni arınma (katharsis) ritüellerindendir. Bir oyuncudan farksız olan birey kurmaca bir sahne ve sanal bir vitrin olarak değerlendirilebilecek ve yeni hayat tarzlarının tasarlanıp kurulduğu sosyal medya ortamında gündelik hayatta biriktiği yaşam enerjisi fazlalığından kurtulma ya da gevşeme; egemenlik kurma ve gerçek hayatta gerçekleştirilmesi mümkün olmayan arzulara ulaşma şansı elde eder ve böylece yeni bir benlik inşa eder.

Sosyal medya üzerinden üretilmiş sanal kimliklerin söz konusu mecrada saygınlığ 1 verme biçimi olarak beğeni ve yorum gibi eylemleri kullandıkları görülmektedir. Elektronik kültür ortamı melez olarak adlandırılabilir, çünkü kişinin sözle söylediklerine diğer kullanıcılar yorumla ya da beğeniyle (like) yani yazıyla cevap vermektedir.

İlkel toplumlardaki statü elde mücadelesi günümüzde dijital ortamda değişerek ve dönüşerek işlev sahibi olarak devam etmektedir. Sosyal medyadaki takipçilerden beğeni kazanma ve yaptıkları eylemlerin paylaşılarak takdir görme isteği, birçok sosyal medya kullanıcısının gerçek hayatta yapmaya cesaret edemeyeceği eylemler için onları teşvik etmektedir. Örneğin; gökdelenlerde ve uçurum kenarlarında öz çekim yapma, vahşi doğada hayvanlarla mücadeleye girişme, yapılamayacak şakaları belirli ortamlarda gerçekleştirme, spor müsabakalarında rakip tribünde kendi takımının lehine tezahüratta bulunma ve bu durumları, sosyal medya ortamlarında paylaşma dijital platformda ilkel toplumlara özgü davranış ritüellerinin yeniden belirmesidir.

\section{SONUÇ}

Çalı̧̧mamızda benlik, kimlik, oyun, tiyatro, maske ve kültür ortamları ilişkisi bireylerin görünümleri ve icraları eylem-temsil bağlamında ele alınmıştır.

Çağımız toplumlarında yaşanan sosyo-kültürel değişimlere bağlı olarak gündelik hayatta ve sosyal medyada ilkelliğin tekrar belirdiği görülür. Sosyal medyada bağlama göre farklılaşan ve çeşitlenen icra performansları insanların yeni ortamlarda çeşitli maskelerle kendilerini güncellediklerinin kanıtıdır. Sosyal medyada inşa edilen benlik, kişinin gündelik hayatta toplum nezdinde elde ettiği benlikle çatışır.

Oyun, ilkel toplumlarda maskelerle birlikte benliğin sunumu ve gösterimi için kullanılan ritüelistik bir eylemdir. Sahnede benliklerin temsilini maskeler aracılığıyla kuran tiyatro 
oyuncularıyla kendilerini özdeşleştiren, fakat gündelik hayatına dair değerlerde sapmalarda bulunmayan Antik Yunan toplumunun aksine "Digital Çağ toplumu", yazılı kültür çağı öncesinin temsili olan ilkel benliklerine tekrar dönme eğilimdedir. Sosyal medya sahnesi ve vitrinindeki maske kullanım çeşitliliği günümüz insanının postmodern arınma (katharsis) ritüellerindendir. $\mathrm{Bu}$ ritüeller çeşitli biçimlerde gerçekleştirilir. Bunlar siyasi, ekonomik ve kültürel içerikli kısa mesaj, tweet ya da retweet, video paylaşımları, durum paylaşımları, yazı ya da görsellerdir. Birey kendisini, gündelik hayatında tepkisiz kaldığı ya da fazla önem vermediği meselelerle ilgili sosyal medya platformlarında paylaşımda bulunarak tasarlanan ve güncellenen yeni benliği üzerinden arındırma çabasına girişir.

Sosyal medya insanların benliklerini sergileyebilecekleri yeni oyun alanları açar. Postmodern durumun her şeye kucak açan yapısından da destek alan ve aynı zamanda denetimsiz bir icra ortamı da olan sosyal medya bireye eylemde ve söylemde hareket özgürlüğü kazandırır. Böylece ilkel bir oyuncu hüviyetine bürünen insan kendisine postmodernizmin çoğulculuk ilkesi sonucunda, üretilmiş ve çoğaltılmış yeni kimliğini inşa etmiş olur. Çünkü bu kimlik sayesinde oyuncu olarak sosyal medya kullanıcısı istediği kişi ya da şeyleri paylaşır, eleştirir, bozar, düzeltir, onaylar ya da reddeder.

\section{KAYNAKÇA}

And, M. (1983). Türk Tiyatrosunun Evreleri. Ankara: Turhan Kitabevi.

And, M. (2012). Oyun ve Bügü Türk Kültüründe Oyun Kavramı (3. Baskı). İstanbul: Yapı Kredi Yayınları.

Aristoteles (2017). Şiir Sanatı Üzerine. A. Çokona ve Ö. Aygün (Çev.) İstanbul: Türkiye İş Bankası Kültür Yayınları.

Atalay, B. (1943). Divanü Lügati’t-Türk Dizini. “Endeks”. Ankara: Alâeddin Kıral Basımevi.

Bakhtin, M. (2016). François Rabelais ve Ortaçağ-Rönesans Halk Kültürü. S. Gürses (Çev.). İstanbul: Alfa

Bourdieu, P. (2014). Seçilmiş Metinler (2. Baskı). L. Ünsaldı (Çev.). Ankara: Heretik Yayınları.

Bourdieu, P. (2015). Ayrım: Beğeni Yargısının Toplumsal Eleştirisi. D. F. Şannan, A. G. Berkkurt (Çev.). Ankara: Heretik Yayınları.

Çil, H. (2017). Bedeni Kurgulamak İslami Romanlarda Beden ve Kimlik. Konya: Çizgi Kitabevi.

Çobanoğlu, Ö. (2007). Türk Dünyası Epik Destan Geleneği. Ankara: Akçağ Yayınları.

Ergin, M. (2011). Dede Korkut Kitabı - I. Ankara: Türk Dil Kurumu Yayınları.

Eker, G. Ö. (2014). İnsan Kültür Mizah Eğlence Endüstrisinde Tüketim Nesnesi Olarak Mizah (2. Bask1). Ankara: Grafiker Yayınları.

Goffman, E. (2014). Günlük Yaşamda Benliğin Sunumu (3. Baskı). B. Cezar (Çev.). İstanbul: Metis Yayınları.

Hayes, N. (2011). Psikolojiyi Anlamak. F. Şar ve A. Hekimoğlu (Çev.). İstanbul: Optimist Yayınları.

Huizinga, J. (2006). Homo Ludens Oyunun Toplumsal İşlevi Üzerine Bir Deneme (2. Baskı). M. A. Kılıçbay (Çev.). İstanbul: Ayrıntı Yayınları.

Işık, İ. E. (1998). Beden ve Toplum Teorisi Öznenin Sosyolojisinden Bedenin Sosyolojisine. (Yayınlanmamış doktora tezi). Mimar Sinan Üniversitesi/ Sosyal Bilimler Enstitüsü, İstanbul.

İnan, A. (1976). Eski Türk Dini Tarihi. Ankara: Milli Eğitim Basımevi. 
Jenkins, R. (2016). Bir Kavramın Anatomisi: Sosyal Kimlik. G. Bostancı (Çev). İstanbul: Everest Yayınlar1.

Mead, H. (2017). Zihin, Benlik ve Toplum. Y. Erdem (Çev.). Ankara: Heretik Yayınları.

Nutku, Ö. (2011). Dünya Tiyatrosu Tarihi I. İstanbul: Mitos Boyut Yayınları.

Ong, W. J. (2014). Sözlü ve Yazılı Kültür Sözün Teknolojileşmesi (5. Baskı). S. Postacıŏlu Banon (Çev.). İstanbul: Metis Yayınları.

Öngören, F. (1996). Antik Mizah ve Dionysos. Güldiken Mizah Kültür Dergisi, 10, 34-38.

Özdemir, N. (2005). Cumhuriyet Dönemi Türk Eğlence Kültürü. Ankara: Akçağ Yayınları.

Park, R. E. (1950). Race and Culture. Illinois: The Free Press.

Sanders, B. (2013). Öküzün A'sı Elektronik Çağ'da Yazılı Kültürün Çöküşü ve Şiddetin Yükselişi (3. Baskı). Ş. Tahir (Çev.). İstanbul: Ayrıntı Yayınları.

Szerb, A. (2008). Dünya Yazın Tarihi. Ankara: Dost Kitabevi Yayınları.

Şener, S. (2011). İnsanı Geçitlerde Sınayan Sanat Dram Sanatı (2. Baskı). İstanbul: Mitos-Boyut Yayınlar1

Şener, S. (2016). Dünden Bugüne Tiyatro Düşüncesi (10. Bask1). Ankara: Dost Kitabevi Yayınları.

Tekin, O. (1998). Eski Yunan Tarihi (2. Bask1). İstanbul: İletişim Yayınları.

Topçuoğlu, A. (1995). Modernleşme Sürecinde "Bireyin" Dönüşümü ve Yaşantının Meşruluğu Sorunu. Selçuk Üniversitesi Fen-Edebiyat Fakültesi Edebiyat Dergisi, 9-10, 127-138.

Y1ldırım, A. F. (2019). Farklılıklar ve Ötekileştirme. Konya: Çizgi Kitabevi. 